\title{
Different Human-Dog Interactions in Early Agricultural Societies of China, Revealed by Coprolite
}

\section{OPEN ACCESS}

Edited by: Guanghui Dong,

Lanzhou University, China

Reviewed by:

Jianping Zhang,

Chinese Academy of Sciences, China

Yimin Yang,

University of Chinese Academy of

Sciences, China

*Correspondence:

Yunan Zhang

ynzhang@itpcas.ac.cn

Xiaohong Wu

wuxh@pku.edu.cn

Specialty section:

This article was submitted to

Quaternary Science, Geomorphology

and Paleoenvironment,

a section of the journal

Frontiers in Earth Science

Received: 26 November 2020

Accepted: 30 December 2020

Published: 16 February 2021

Citation:

Zhang $Y$, Sun G, Zhang $D$, Yang $X$ and

Wu X (2021) Different Human-Dog

Interactions in Early Agricultural

Societies of China, Revealed

by Coprolite.

Front. Earth Sci. 8:633724.

doi: $10.3389 /$ feart.2020.633724

\author{
Yunan Zhang ${ }^{1,2 *}$, Guoping Sun ${ }^{3}$, Dong Zhang ${ }^{4}$, Xiaoyan Yang $^{2}$ and Xiaohong $\mathrm{Wu}^{1 *}$ \\ ${ }^{1}$ School of Archaeology and Museology, Peking University, Beijing, China, ${ }^{2}$ Institute of Tibetan Plateau Research, Chinese \\ Academy of Sciences, Beijing, China, ${ }^{3}$ Zhejiang Provincial Institute of Relics and Archaeology, Hangzhou, China, ${ }^{4}$ Institute of \\ Archaeology, Chinese Academy of Social Sciences, Beijing, China
}

Dogs served in a variety of capacities in prehistory. After their domestication in Paleolithic hunter-gatherer societies, the emergence of agriculture shifted their partnerships with people. However, the associations between dogs and early farmers are not readily visible in the archaeological record. In the present study, dog coprolites, uncovered from two groups of early agricultural societies in China during the Neolithic Age, the early rice agricultural site of Tianluoshan in the lower Yangtze River, and three early millet-rice mixed agricultural sites of Shuangdun, Yuhuicun, and Houtieying along the middle Huai River, were examined based on the comparisons of lipid and palynological results to reveal different relationships of dogs and humans. The Tianluoshan dogs showed a plantdominated diet with higher contents of plant sterols and fatty alcohols with longer chain lengths. Dogs may have lived on foraging or been provisioned with refuse for the cleanness purpose. On the contrary, dogs from the sites of Shuangdun, Yuhuicun, and Houtieying showed a meat-dominated diet with higher proportions of animal sterols and short-chain fatty alcohols. It most probably referred to their assistance in hunting and thus being provisioned with meat. Furthermore, activity areas of the dogs also reflect different deployment strategies and agricultural systems, evidenced by pollen spectra from the coprolites. Dogs at Tianluoshan mostly appeared in the rice field area, in correspondence with the labor-consuming rice cultivation as the main targeted resource, showing their participation in daily agricultural activities. On the other hand, high concentrations of pollen from forest and grassland revealed that hunting dogs played a regular role in the early millet-rice mixed farming societies, probably related to the importance of hunting activities in the daily subsistence.

Keywords: coprolite, human-dog interaction, China, Lower Yangtze Region, Huai River Region, subsistence

\section{INTRODUCTION}

As the first domestic animal, current archaeological and genetic evidence suggest that dogs emerged during the Late Pleistocene (Germonpré et al., 2009, Germonpre et al., 2012; Ovodov et al., 2011; Larson et al., 2012). Historical records revealed that dogs participated in every aspect of human societies, helping in hunting, waste disposal, protection of people and belongings, guarding, entertainment, sacrifice, and offering (Vigne and Guilaine, 2004; Digard, 2006; Méniel, 2006; Horard-Herbin et al., 2014). However, in spite of the various capacities of dogs, few are 
perceivable in archaeological evidence, thus often remaining ambiguous (Lupo, 2011). With regard to Paleolithic Age when dogs joined hunting-gathering people, most research heavily relied on ethnographic records and emphasized their role of assistance for hunting in Late Pleistocene times, which greatly enhanced hunting productivity and catalyzed human population growth and spread (Lupo, 2017; Morey and Jeger, 2017). When agriculture emerged in the Neolithic Age, human-dog relationships may have changed, but it has rarely been discussed due to the lack of direct evidence. It has been assumed that the different functions of dogs in societies are correlated with variations in human subsistence and the reliance on resource categories (Lupo, 2019). It thus raises the questions of whether dogs continued helping with hunting among agricultural people living in permanent villages, when hunting success was not a crucial part for subsistence, and whether dogs were treated variably in different agricultural systems.

Dog coprolites have been uncovered in many prehistoric dwellings (e.g., Toker et al., 2005; Tolar and Galik, 2019; Borry et al., 2020), which indicated that they shared the same habitats with humans. Compared with traditional isotope analysis providing a rough dietary measurement and a broad signal of the average lifetime diet (e.g., Guiry, 2012), coprolites have the potentials to contribute to reconstructing the detailed diet of dogs and provide multiple lines of supporting evidence. Their high temporal resolution enables us to explore patterns of yearly, monthly, or even daily variability in diets. Lipids that normally appear in feces such as sterols and bile acids have been used as species indicators, but together with other molecules, they have the potentials to be applied as dietary indicators (Shillito et al., 2020).

In agricultural societies, different farming systems and subsistence strategies may leave traces in the diets of dogs. Dog coprolites uncovered from the early rice agricultural site of Tianluoshan in the Lower Yangtze Region, and three early millet-rice mixed agricultural sites of Shuangdun, Yuhuicun, and Houtieying along the middle Huai River, have been analyzed in the previous studies (Zhang et al., 2019; Zhang et al., 2020). All of the four sites were dated back to Middle-Late Neolithic Age (ca. 7000-5000 B.P.), an important time frame with transformation from hunter-gatherers to early farmers in prehistoric China. Our preliminary results showed that distinct lipid and palynological signals from the dog coprolites at two groups of sites indicate different diets of dogs and their living environments. By summarizing and comparing the above data, in the present study we intend to integrate lipid and palynological data to reveal different human-dog interactions. The results may further provide evidence of their associated agricultural systems and subsistence strategies.

\section{ARCHAEOLOGICAL BACKGROUND AND THE STUDY SITE \\ Rice Agriculture in the Lower Yangtze Region and the Tianluoshan Site}

Lower Yangtze Region has been widely recognized as one of the subcenters of rice domestication (Fuller et al., 2009; Nakamura,
2010; Gross and Zhao, 2014), and the domestication began as early as 10,000 B.P. or so at Shangshan (Zheng et al., 2016; Zuo et al., 2017). During the Middle Neolithic Age, rice remains including a minority of domesticated forms were found at Kuahuqiao (8,200-7000 B.P.), although the hunting-gathering subsistence still dominated (Zong et al., 2007). At a later stage, Hemudu (7000-5000 B.P.) is the representative culture of the Late Neolithic Age. A huge number of plant remains have been recovered in 1970s due to waterlogged condition of the site, among which the most noticeable were rice.

During the same period, dog remains of domesticated type have been uncovered in the Lower Yangtze Region. Morphometric data of dog remains from Kuahuqiao showed shortened dentition lengths, suggesting the domestication process has begun (Yuan and Yang, 2004). The sizes of the Hemudu dogs were similar to the modern domestic dog specimens and significantly smaller than wolves (Zhang, 2015).

Tianluoshan, a typical site of the Hemudu Culture, has been thoroughly excavated and studied in multidiscipline since 2004. Artifacts and radiocarbon dating analysis indicated that the lowest layers (8th and 7th layers) were dated back to ca. $7000-6,500 \mathrm{cal}$. B.P., representing the early phase of the Hemudu Culture. The 6-5th and 4-3rd layers of the Tianluoshan site were dated ca. 6,500-6,000 cal. B.P. and ca. $6,000-5,500 \mathrm{cal}$. B.P., comparable to the Middle and Late Hemudu Culture (Zhejiang Provincial Institute of Cultural Relics and Archaeology, 2007; Zhang, 2015).

An increased proportion of domesticated rice relative to wild gathered foods (Fuller et al., 2009) indicated the significance of rice domestication at Tianluoshan. Based on pollen, diatom, seed, and phytolith analysis, paddy fields reclaimed from wetlands provided suitable habitats for rice cultivation ( $\mathrm{Li}$ et al., 2012; Zheng et al., 2012). Large amounts of acorns were uncovered from storage pits, indicating gathering activities in the mountain areas (Qin et al., 2010). It has also been speculated that forest edge was under human management through the analysis of wild fruits and seeds (Pan, 2011).

The analysis of the faunal remains pointed to the hunting of sika deer (Cervus nippon), sambar (Cervus unicolor), and muntjac (Muntiacus reevesi). Other mammal species including pig (Sus sp.), water buffalo (Bubalus mephistopheles), and a huge amount of freshwater fish (e.g., Carassius auratus, Channa argus) also provided meat income (Zhang, 2015). Dog is the only assured domestic animal at Tianluoshan, although it only accounted for $0.1 \%-0.2 \%$ of the identified specimens (Zhang, 2015).

\section{Millet-Rice Mixed Farming Along the Huai River and the Shuangdun, Yuhuicun, and Houtieying Sites}

The Huai River Valley, situated between the Yangtze and Yellow Rivers, is a core area for cultural exchange between northern and southern China. The interplay of rice and millet farming is the characteristic agricultural system in the Huai River Valley (Yang et al., 2016).

In the upper Huai River Valley, Jiahu (9,000-7800 B.P.) and Peiligang (9,000-7000 B.P.) are two representative cultures of the 


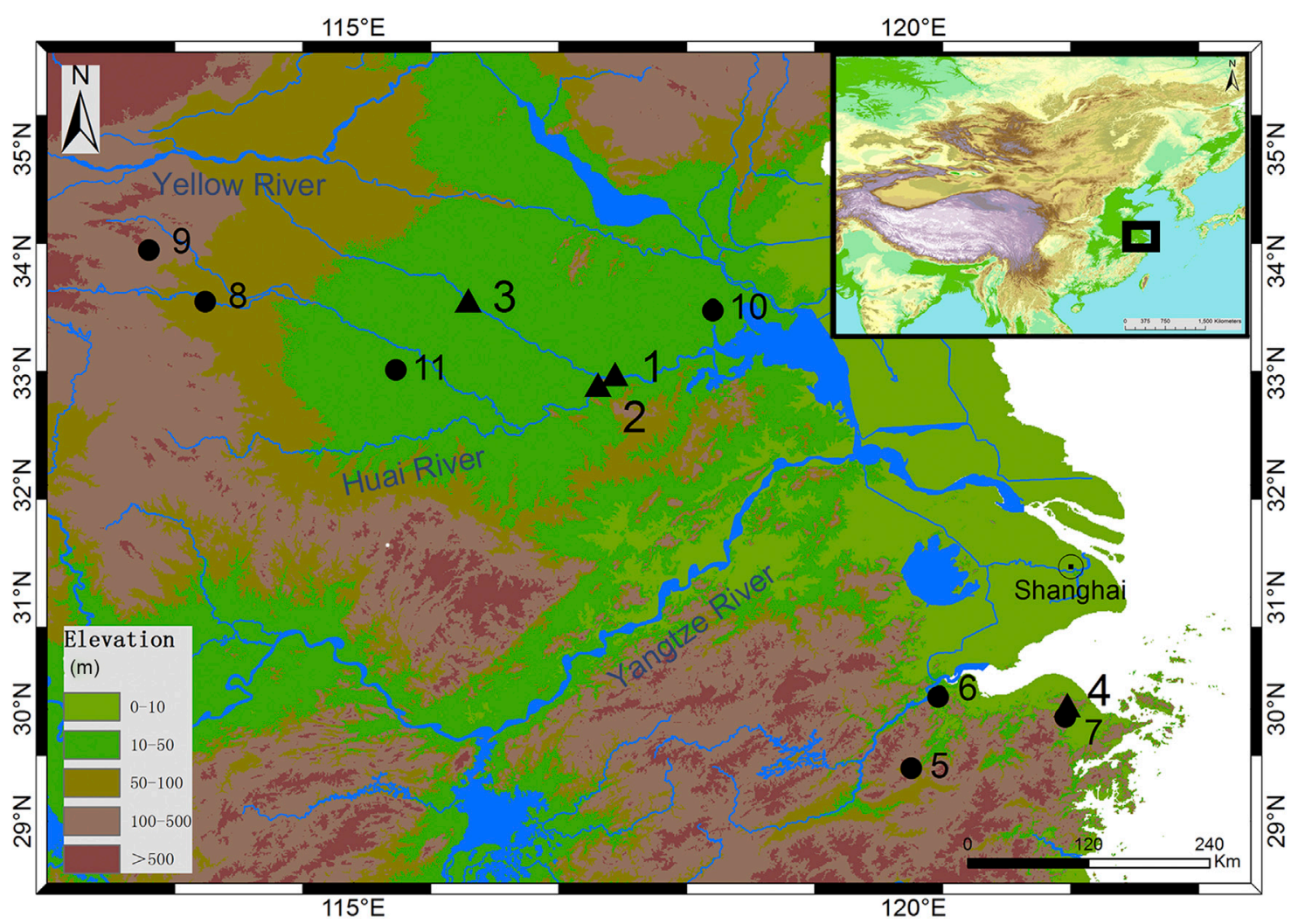

FIGURE 1 | Locations of the sites for study and other sites mentioned in the text (1. Shuangdun; 2. Yuhuicun; 3. Houtieying; 4 . Tianluoshan; 5. Shangshan; 6. Kuahuqiao; 7. Hemudu; 8. Jiahu; 9. Tanghu; 10. Shunshanji; 11. Gongzhuang; black triangles indicate the sites for coprolite analysis in this study and black dots indicate the sites mentioned in the text).

Middle Neolithic Age. The analyses of the plant and animal remains indicated that rice was the only crop that appeared in large quantity at Jiahu and that a hunter-gatherer subsistence still formed the major part of the Jiahu economy (Zhang and Hung, 2013). Intentionally buried dogs were uncovered at Jiahu in cemeteries and beside houses (Henan Province Institute of Relics and Archaeology, 1999), indicating a strong relationship between human and dogs. The shortened dentition length of dogs showed that domestication progressed (Yuan, 2001). Phytolith analysis showed a broomcorn millet and rice mixed farming in the Peiligang Culture from 7800 B.P. at Tanghu (Zhang et al., 2012).

In the middle and lower Huai River Valley, Shuangdun (7300-6800 B.P.) and Shunshanji (8,500-7000 B.P.) are two representative Middle-Late Neolithic cultures, respectively. In the Shuangdun cultural sites, the analyses of seeds and starch grains emphasized the gathering of wild tuberous plants and rice was cultivated on a small scale (Dong et al., 2014; Cheng et al., 2016). As no millet remains were found, Shunshanji is supposed to have relied on rice farming, although a wide range of plant resources was detected by starch grain analysis including, e.g., Coix lacryma-jobi, Triticeae, Oryza sativa, and Trichosanthes kirilowii, indicating that gathering was still the main strategy (Yang et al., 2016; Luo et al., 2020).
At a later stage, Dawenkou Culture Period was an important stage for subsistence transformation from low-level food production to prehistoric agriculture (Luan, 2013). During early Dawenkou Period, although few sites have been studied, phytoliths from Gongzhuang showed a rice-dominated agriculture (Luo et al., 2018). During late Dawenkou Period, the cultivation of millet and broomcorn millet developed along the Huai River, integrated with the rice farming tradition (Cheng, 2020).

The three study sites, Shuangdun, Yuhuicun, and Houtieying, are situated in Anhui Province, along the mainstream and tributary of the Huai River (Figure 1). Shuangdun is the representative site of the Shuangdun Culture. Radiocarbon dating and stratigraphy showed that the Shuangdun site was dated back to 7300-6800 B.P. (Anhui Provincial Institute of Cultural Relics and Archaeology and the Museum of Bengbu, 2008). Sherds with special symbols, stone tools, clay sculptures, and abundant animal bones were discovered during the excavation in 1991-1992 and 2014 (Institute of Archaeology of Chinese Academy of Social Sciences and Museum of Bengbu, 2016). Phytoliths extracted from the sediments revealed that rice was the most common crop, while broomcorn millet appeared occasionally (Luo et al., 2019). At Yuhuicun, cultural remains recognized as the Shuangdun Culture (ca. 7000 B.P.) were 
uncovered during the excavation in 2017. More than 90 pits filled with sherds, bones and burnt soil, 160 column holes, and large wall base and living floor were discovered, exposing the planning of settlement and large constructions during the Shuangdun Period. Based on pottery morphology, Houtieying was identified as a typical site of Early-Middle Dawenkou Culture Period (ca. 6,500-6000 B.P.). During 2015 and 2016, systematic excavations revealed houses and pits, verifying the location of the settlement. Zoological analysis showed that deer and wild boar hunting provided the meat income, accompanied with a small number of Lamellibranchia. Domestic pigs also appeared at the site, indicating an early stage of pig husbandry (Dai and Zhang, 2018). At the three study sites, more than 100 coprolites have been uncovered at Shuangdun; however, only very few suspicious dog bones have been found at Shuangdun and Houtieying.

\section{MATERIALS AND METHODS}

103 dog coprolites were uncovered at Tianluoshan, in the 8th and 7 th layers of trenches 205, 206, 301, 304, 305, 306, 403, 404, 405, and 406 , within the main residential area of the early occupation period (ca. 7000 and 6,500 cal B.P.) (Zhejiang Provincial Institute of Cultural Relics and Archaeology, 2007). The coprolites were coded based on trench, layer, and sequential numbers (Supplementary Material). The palynological results have been published in Zhang et al. (2019) and in the present study all the lipid data were supplemented for comparative analysis.

The Yuhuicun and Houtieying coprolites originating from human and dogs were found in pits and excavated layers, usually accompanied with animal bones and dating back to the Shuangdun Cultural Period (ca. 7300-6800 B.P., Anhui Provincial Institute of Cultural Relics and Archaeology and the Museum of Bengbu, 2008) and the Early-Middle Dawenkou Culture Period (ca. 6,500-6000 B.P.), separately. All the pollen and lipid data from Yuhuicun and Houtieying have been published in Zhang et al. (2020). Here the results of dog coprolites from Yuhuicun and Houtieying were selected for comparison, including eight from Yuhuicun and four from Houtieying. Samples were named based on abbreviation of the site (Yuhuicun-YHC, Houtieying-HTY) and sequential numbers (Supplementary Material).

At Shuangdun, more than 100 coprolites were uncovered during the excavation. Most of them contain large bones with burnt inclusions. Based on morphology and contents, they have been identified as dog origin. However, probably because most coprolites have been burnt with animal bones and other objects, few pollen grains and lipid residues have been preserved. Therefore, in this paper only seven coprolites from Shuangdun were included to provide a general view and they were named based on abbreviation of the site (Shuangdun-SD) and sequential numbers (Supplementary Material).

To summarize the results and make the comparison, all the lipid and pollen data from the above sites were recalculated using new ratios to display the general pattern. All the new data from two groups of sites were compared and linked to their archaeological background for further interpretations in order to draw new conclusions.

\section{Lipids}

Fecal sterols in feces form from the gut through bacterial reduction of dietary sterols and have been widely used to distinguish the origins of the fecal materials. There are also potentials to assess the fecal lipids and other organic molecules as indicative of dietary preferences (Leeming et al., 1996; 1997). Through comparing the proportions of animal- and plant-derived sterols in the feces, it can give an indication of the relative inputs of meat and plants in the diets, which has been applied to the discussions of the diets of Neanderthals and nonhuman primates (Sistiaga et al., 2014; 2015). In dog feces, a special feature is the absence of $5 \beta$-stanols due to the lack of specific bifidobacteria inhibiting the production of $5 \beta$-stanols (Leeming et al., 1996). Therefore, fecal sterols in dog coprolites are less affected by biosynthesis processes during digestion and may directly represent the proportions of plant and animal intake from diets.

In the experimental procedures, all samples were ground with mortar and extracted with dichloromethane/methanol (DCM/ $\mathrm{MeOH})$ through Accelerated Solvent Extraction or ultrasonication. For the Tianluoshan coprolites, the extracts were gradient eluted using three separate solvents: hexane, hexane/DCM (4:1), and DCM/ methanol (9:1). Alcohols and fatty acids were further fractionated with DCA/acetone (9:1) and 2\% formic acid in DCM as elutions using an aminopropyl-coated stationary phase, and then the alcohol fraction was derivatized. To avoid loss, samples from Shuangdun, Yuhuicun, and Houtieying were directly derivatized by adding $50 \mu \mathrm{L}$ of N,O-bis(trimethylsilyl)trifluoroacetamide (BSTFA) containing 1\% trimethylchlorosilane (TMCS) and $50 \mu \mathrm{L}$ hexane and heating at $70^{\circ} \mathrm{C}$ for $1 \mathrm{~h}$. Gas chromatography mass spectrometry (GC/MS) analysis was conducted using an Agilent 7890A-5975C GC-MS equipped with HP-5MS column or a ThermoQuest TraceMS GC-MS equipped with DB5 column. $N$-alkanes, $n$-alcohols, and steroids were identified based on their mass spectra and the comparison of the retention times with standards.

Thirty-one coprolites from Tianluoshan and eight coprolites from Shuangdun, Yuhuicun, and Houtieying yielded detectable concentrations of lipids which were chosen for the comparison of lipid data. To summarize the proportions of plant- and animalderived food in diets, the ratios of animal and plant sterols were calculated using the data from two groups of sites. The sum of animal sterols includes coprostanol, epicoprostanol, cholesterol, cholestanol, cholestan-3-one, and cholest-5-en-7-one. The sum of plant sterols includes 5 $\beta$-stigmastanol, $5 \beta$-campestanol, sitosterol, and $5 \alpha$-stigmastanol. As fatty alcohols were best preserved in the coprolites, average chain lengths of fatty alcohols were also calculated for each sample. $T$ test was adopted to determine if there is significant difference in average chain lengths between two groups of sites. $p$ value of 0.01 was used as criterion.

\section{Pollen}

Pollen contents of coprolites can provide valuable information on past vegetation and landscape (e.g., Yll et al., 2006; Wood et al., 
2012; Taylor et al., 2020). It has been proposed that the dung pollen record may reflect the vegetation of the visiting areas of its producer or their prey (Carrión et al., 2001) and the range of habitats (Djamali et al., 2011). As an analogue, the palynological data from the coprolites of dogs in an archaeological context may also indicate the surrounding vegetations where they have visited.

In the experiments, extraction procedures for pollen grains followed Faegri et al. (1989), including $\mathrm{KOH}$ digestion, sieving (meshes $120 \mu \mathrm{m}$ ), bromoform-ethanol mixture (specific gravity 2) extraction, and acetolysis. To avoid any possible damage to the pollen grains, pretreatment procedures for the Shuangdun, Yuhuicun, and Houtieying coprolites only included digestion with $2 \mathrm{~N} \mathrm{HCl}$, sieving (meshes $355 \mu \mathrm{m}$ ), and zinc bromide (specific gravity 2) extraction. For each sample, a minimum of 300 pollen grains were identified and calculated as percentages. Considering the high frequencies of Typha pollen probably from local origin at Tianluoshan, Typha was excluded from the pollen sum for percentage calculations.

To compare the differences between two groups of sites, pollen data of eighty-two coprolites from Tianluoshan and ten coprolites from Yuhuicun and Houtieying that yielded enough pollen grains for counting were summarized into ecological groups based on the growth environment of the plants, i.e., wetland herbs, upland herbs, shrubs, and trees. In addition, large Poaceae $(35-39 \mu \mathrm{m}$ and $>40 \mu \mathrm{m}$ ) pollen has been identified as criterion to represent the development of rice farming at Hemudu (Wang et al., 2010; Liu et al., 2016). Therefore, large Poaceae (35-39 $\mu \mathrm{m}$ and $>40 \mu \mathrm{m})$ was selected to represent rice field vegetation and Poaceae (< $35 \mu \mathrm{m})$ was categorized into upland herbs.

\section{RESULTS}

\section{Lipids}

Within the thirty-one coprolites analyzed from Tianluoshan, twenty-six show higher proportions of plant sterol, ranging from $53.13 \%$ to $96.63 \%$ (average $72.26 \%$ ), and less animal sterol, ranging from $3.37 \%$ to $46.85 \%$ (average $27.74 \%$ ). Only five samples contain animal sterol of more than $50 \%$, ranging from $53.69 \%$ to $94.53 \%$. On the contrary, six coprolites from Yuhuicun and Houtieying contain $100 \%$ of animal sterol. The other two samples from Houtieying show equal contents of animal and plant sterols, with the plant sterol slightly higher. In addition, only trace amount of cholesterol was detected in one coprolite from Shuangdun.

Similarly, coprolites from Tianluoshan exhibit similar average chain lengths, ranging from 19.34 to 23.84 (average 21.35, stdev 0.81 ). The average chain length values of samples from Shuangdun, Yuhuicun, and Houtieying range from 12.41 to 26.56 (average 20.57, stdev 4.96), relatively lower than that of the Tianluoshan coprolites (Figure 2). The large variations between samples (stdev 4.96) from Yuhuicun and Houtieying are in correspondence with the sterol profiles such that they are either dominated by animal sterol or show a mix of plant and animal sterols. Probably because of this variation, the $p$ value of 0.55 indicates that there is no significant difference in average chain lengths between two groups of sites.

\section{Pollen}

Large Poaceae pollen is the prevalent pollen species in most samples from Tianluoshan. Fourty-nine coprolites show large Poaceae pollen with highest proportions, ranging from $28.30 \%$ to $85.07 \%$. They are either predominated by large Poaceae or accompanied with relatively higher percentages of arbor and upland herbs. Arboreal pollen reaches highest frequencies in eighteen samples (26.46\%-77.74\%). Quercus usually shows highest values, with other species including Castanopsis, Liquidambar, Pinus, and Ulmus, and upland herbs usually also reach higher values. The other fifteen samples are dominated by shrub pollen (43.81\%-94.16\%), with abundant species including Rosaceae, Astragalus, Uncaria, Mallotus, and arboreal and large Poaceae pollen to a lesser extent. Generally, upland herbs and wetland herbs occur less frequently in all samples.

On the other hand, five coprolites from Yuhuicun and one from Houtieying are dominated by arboreal pollen (90.00\%-96.00\%). Quercus is the most abundant pollen taxon, with percentages between $85.71 \%$ and $95.67 \%$. Pollen from upland herbs is in lower percentages and wetland herbs occur more sporadically. Other samples mainly contain pollen from upland herbs $(42.00 \%-95.36 \%)$. Poaceae is generally abundant and Artemisia reaches the highest frequency in YHC-9. In YHC-7, wetland herbs dominated by Typha are prevalent (Figure 3).

\section{DISCUSSION}

\section{Implications of Dog Provisions and Their Role in Human Subsistence}

Based on the sterol compounds, our results generally reflect a plant-dominated diet at Tianluoshan and a meat-dominated diet at Shuangdun, Yuhuicun, and Houtieying. Clusters of large undigested bone remains are present in the coprolites from the latter sites, also indicating the meat intake. At Tianluoshan, impressions of plant materials can be observed (Figure 4). The sterol profiles are in correspondence with the average chain lengths of fatty alcohols that the samples from Tianluoshan contain more fatty alcohols with long chain lengths from the input of leaf waxes. However, compared with the lipid data from Tianluoshan, results from Yuhuicun and Houtieying are more fluctuated, with samples either dominated by cholesterol and cholestanol or showing higher input of plant sterols and wider distributions of fatty alcohols.

It has been assumed that there will be dietary variations between wild canine populations that subsist on a diversity of resources (including human refuse) and domestic dogs that rely on domestic waste and human provisioning (Lupo, 2019). Barton et al. (2009) classified the above two types of dogs appearing at Dadiwan, a Middle Neolithic site in northern China: 1) "camp followers" wild-foraging dogs that benefited from a close association with humans and 2) camp-fed, behaviorally domestic dogs that lived and hunted with humans. The second type of dogs consumed more animal products and millets than did wild-foraging dogs, implying the intentional provisioning by humans. 
Rice farming settlement

Rice-millet farming settlement

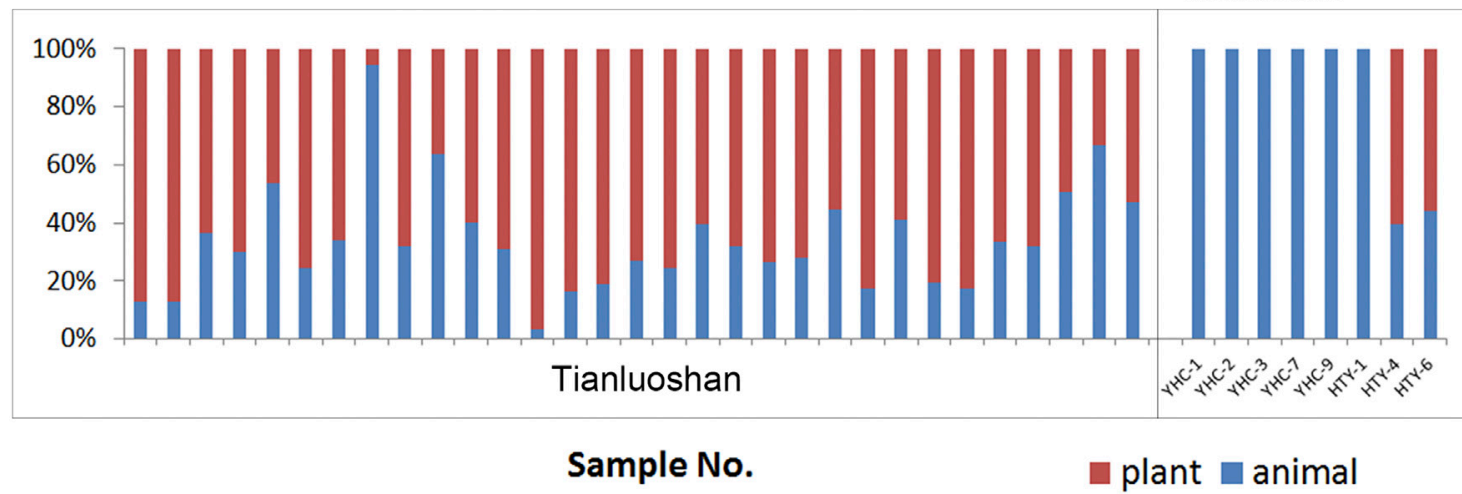

FIGURE 2 | Proportions of plant- and animal-derived sterols in coprolites recovered from rice farming settlement and mixed farming settlements.

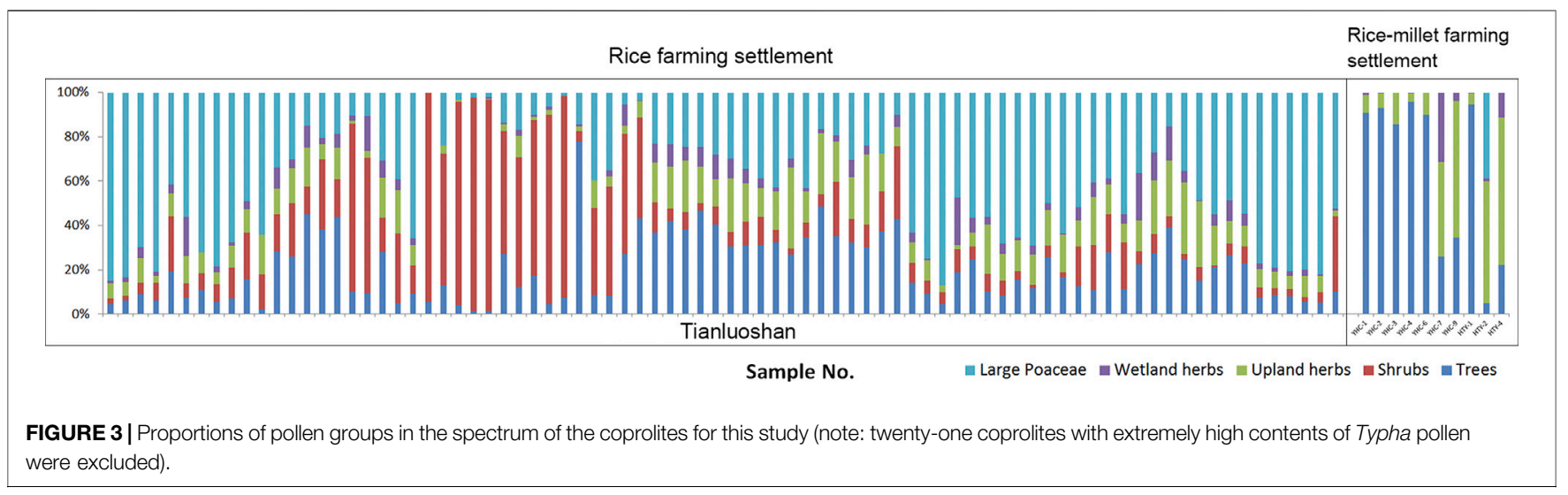

Using the above classifications, it can be distinguished that the dogs at Tianluoshan were more similar to the "camp followers" at Dadiwan that may have fed on domestic scraps. The sedentary and agricultural lifestyle at Tianluoshan may have supplied predictable and stable anthropogenic refuse for their diets to rely on scavenging discarded food waste. Caceotrophy, the consumption of feces commonly found in dogs, may have provided extra nutrients.

On the other hand, Shuangdun, Yuhuicun, and Houtieying dogs consumed higher proportions of meat, more similar to the camp-fed, behaviorally domestic dogs at Dadiwan. It is highly probable that they assisted with hunting because hunting dogs usually consume more meat, and the canine population used for hunting could only be sustained with intentional provisioning by humans. Otherwise, ethnographic records revealed that anthropogenic food refuse from small-sized villages could not establish or support an indigenous working dog population as canid scavengers (Lupo, 2019). The fluctuated diets may rely on the outcome of hunting and thus the feasibility of meat. At Houtieying, more plant input from dogs' diets may also relate to the less dependence on hunting at a later stage. However, as only the coprolites left in the site were examined, the results could only represent the diets when dogs were wandering around the site. We cannot rule out the possibility that the Tianluoshan dogs may have participated in hunting activities but left the feces in other temporary camps, where they also had a meatdominated diet.

Furthermore, the food of dogs is also in correspondence with human diet. Lipid analysis of pottery residues at Tianluoshan has revealed that the pottery was largely used for processing starchy plant foods, yet the evidence for processing fish was very limited (Shoda et al., 2018), similar to the dominated plant intake of dogs. On the contrary, animal bones were uncovered in large quantities at Shuangdun, Yuhuicun, and Houtieying, depicting the subsistence relying on animals. A similar phenomenon was observed at the early Neolithic site of Jiahu, where large amounts of suspected dog coprolites were found. Hunting tools account for $49.2 \%$ of the Jiahu artifacts, above fishing tools $(24.8 \%)$ and agricultural tools $(26 \%)$, indicating a meatdominated lifestyle (Lai et al., 2009).

Comparing the diets of humans and dogs, it can be concluded that dogs at all sites were permitted to roam freely and scavenge domestic refuse, thus their diets highly overlapped with that of humans. However, different human-dog relationships still 

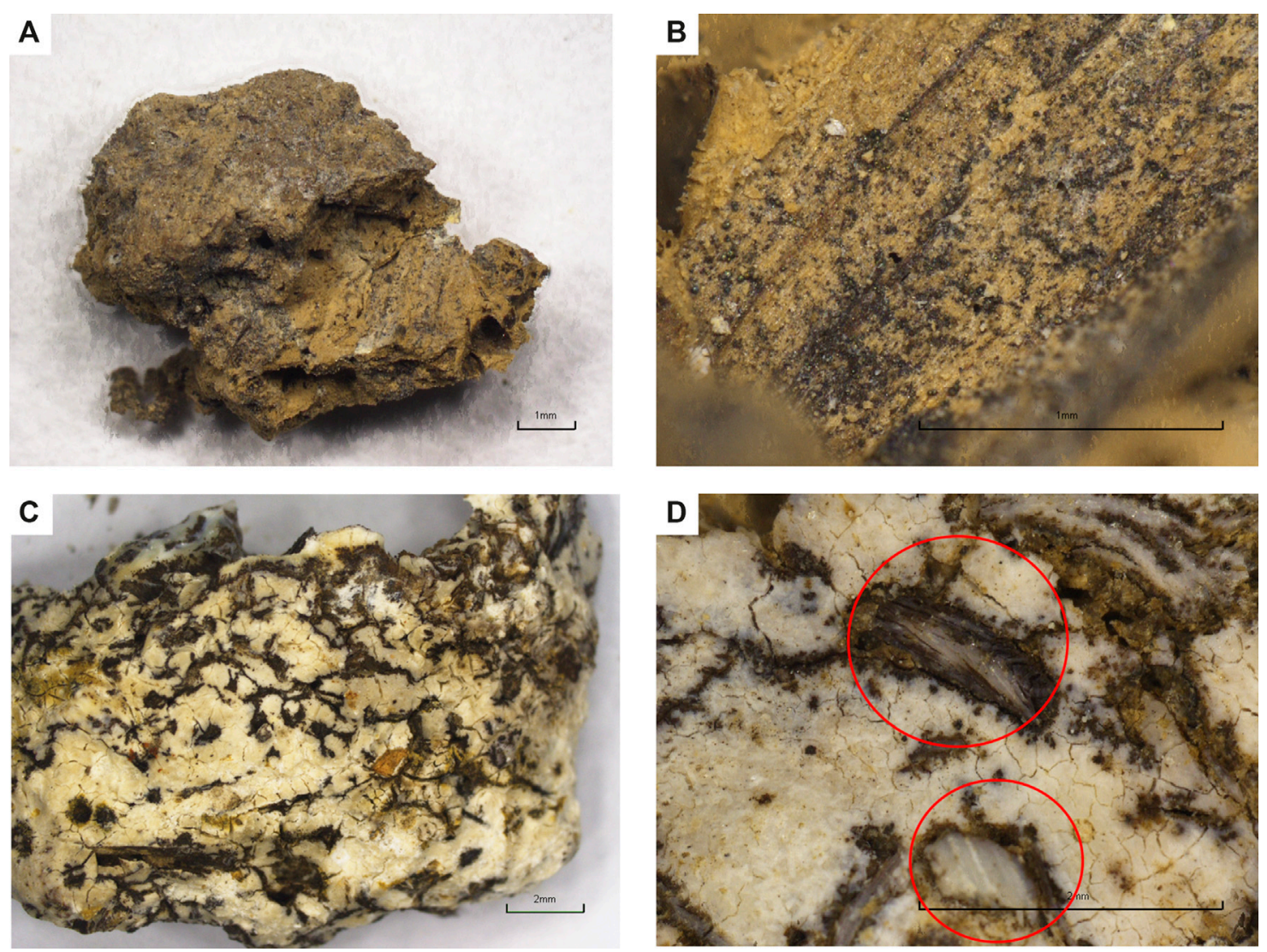

FIGURE 4 | Microscope photos of the cross sections of the coprolites. (A) Tianluoshan coprolite with incorporated plant materials. (B) Reticulate impressions of plant remains from the Tianluoshan coprolite. (C) Undigested bone fragments from the Yuhuicun coprolite. (D) Small bones (marked in red circle) incorporated in the Yuhuicun coprolite.

existed at two groups of sites. The Tianluoshan dogs may have relied on foraging of daily waste and used it for cleaning purpose, at least. Through consuming human waste, their existence in the food chain also accelerated the recycling of organic materials at the site. On the other hand, at Shuangdun, Yuhuicun, and Houtieying, hunting dogs may have been intentionally provided with meat, which maintained their role as the apex predator.

\section{Activity Areas for Subsistence and Human-Dog Interactions Indicated by Pollen Data}

Pollen spectra from dog coprolites are indicators of the places they have visited and also the frequencies. Comparing the pollen data from Tianluoshan and Shuangdun, Yuhuicun, and Houtieying, the results showed that the Tianluoshan dogs mostly appeared in the rice field area, and scarcely in shrub and forest areas, while the Yuhuicun and Houtieying dogs mainly visited the forest and upland grassland.

Considering the agricultural background at two groups of sites, the perennial wetland rice usually required more labor investment and intensive forms of management (Fuller and
Qin, 2009). Therefore, wetland areas were heavily exploited at Tianluoshan, where dogs also spent most of their time. Moreover, the management of various wild plants has been recorded at Tianluoshan and shrub pollen also appeared in dog feces frequently, showing their similar activity area. Dogs may have accompanied humans for guarding or working in agricultural activities or even been raised for their products such as meat, skin, or bones.

On the contrary, at Yuhuicun and Houtieying, pollen data showed that forest and grassland were the main activity areas for dogs. Their appearance in the Quercus forest is in correspondence with the use of dogs as a hunting tool. At Yuhuicun, although rice and millets may have appeared, evidenced by the phytolith data at Shuangdun (Luo et al., 2019), our results show that hunting may still have been the main function of dogs. As fast-growing, warm-season crops, millets were grown as a low labor investment rain-fed summer crop (Miller et al., 2016). Therefore, compared with the single rice agricultural system at Tianluoshan, labors targeting at other resources in the forest were more available, and dogs may have continued their assistance in hunting. Stable isotope analysis at Dadiwan also suggested that broomcorn millet initially appeared in an economy that relied on hunting and 
dogs were likely the crucial tools in the hunting system of early millet-rice mixed farmers (Barton et al., 2009; Bettinger et al., 2010). At the later stage site of Houtieying, the high concentrations of miliacin and the presence of large Poaceae pollen all point to the existence of dogs in a more stable millet-rice mixed cultivation area, and their role may have transformed to the assistance in farming activities, similar to the domestic dogs at Tianluoshan.

\section{CONCLUSION}

Lipid and pollen data from dog coprolites uncovered from two groups of sites, i.e., Tianluoshan and Shuangdun, Yuhuicun, and Houtieying, were compared to reveal their different dietary components and associated human-dog relationships. The Tianluoshan dogs had more plant intake, indicating the foraging of domestic waste, while the Shuangdun, Yuhuicun, and Houtieying dogs consumed more meat, revealing human intentional provision. The results imply that the Shuangdun, Yuhuicun, and Houtieying dogs may have participated in hunting and the Tianluoshan dogs lived as "camp followers." Furthermore, the activity areas of the Tianluoshan dogs were highly centered at the rice fields, while the Yuhuicun and Houtieying dogs mostly appeared in the forest and grassland. The results show that dogs were mainly used in the wetland-based early rice farming system at Tianluoshan and in the hunting-dominated subsistence at Yuhuicun. At a later stage, millet agriculture with low labor investment developed at Houtieying, but hunting still made up part of the food income. Compared with archaeological evidence from Paleolithic sites, our results showed that dogs were used for multifunctions in early farming societies. Dogs in early rice-millet mixed farming settlements continued participating in hunting, while in early rice agricultural settlement, dogs may have played regular role in farming habitats.

\section{REFERENCES}

Anhui Provincial Institute of Cultural Relics and Archaeology, and the Museum of Bengbu (2008). Bengbu Shuangdun: excavation report of neolithic sites. Beijing, China: Science Press [in Chinese, with English summary].

Barton, L., Newsome, S. D., Chen, F. H., Wang, H., Guilderson, T. P., and Bettinger, R. L. (2009). Agricultural origins and the isotopic identity of domestication in northern China. Proc. Natl. Acad. Sci. U.S.A. 106 (14), 5523-5528. doi:10.1073/ pnas.0809960106

Bettinger, R. L., Barton, L., and Morgan, C. (2010). The origins of food production in north China: a different kind of agricultural revolution. Evol. Anthropol. 19 (1), 9-21. doi:10.1002/evan.20236

Borry, M., Cordova, B., Perri, A., Wibowo, M., Prasad Honap, T., Ko, J., et al. (2020). CoproID predicts the source of coprolites and paleofeces using microbiome composition and host DNA content. PeerJ 8, e9001. doi:10. 7717/peer. 9001

Carrión, J. S., Riquelme, J. A., Navarro, C., and Munuera, M. (2001). Pollen in hyaena coprolites reflects late glacial landscape in southern Spain. Palaeogeogr. Palaeoclimatol. Palaeoecol. 176 (1-4), 193-205. doi:10.1016/s0031-0182(01) 00338-8

\section{DATA AVAILABILITY STATEMENT}

Publicly available datasets were analyzed in this study. This data can be found here: https://doi.org/10.1016/j.revpalbo.2019.104101, https://doi.org/10.1016/j.jasrep.2019.102135.

\section{AUTHOR CONTRIBUTIONS}

$\mathrm{YZ}$ and XW designed the research. YZ performed the experiments and wrote the manuscript. DZ and GS provided samples for this study. XY and XW revised the manuscript, with contributions from all authors.

\section{FUNDING}

This work was supported by the National Natural Science Foundation of China (41771231) and the China Scholarship Council ((2017)3109).

\section{ACKNOWLEDGMENTS}

We thank Yingliang Yang, Kai Wang, Zhenhua Deng, Bas van Geel, Annemarie Philip, Britte Heijink, and Samira Absalah, for help with the experiments, and Bas van Geel, William D. Gosling, C. N. H. McMichael, and Boris Jansen for help with the interpretations. We also appreciate the editor and two reviewers who gave valuable suggestions for revisions.

\section{SUPPLEMENTARY MATERIAL}

The Supplementary Material for this article can be found online at: https://www.frontiersin.org/articles/10.3389/feart.2020.633724/ full\#supplementary-material.

Cheng, Z. (2020). A preliminary study on prehistoric agriculture during Dawenkou culture period in Huaihe river basin of Anhui provi. Nongye Kaogu 1, 22-28. doi:10.06-2335(2020)01-0022-07[in Chinese, with English summary].

Cheng, Z., Yang, Y., Zhang, J., Fang, F., Yu, J., Chen, B., et al. (2016). Research on charred plant remains from the Xiaosungang site in Huainan city, Anhui Province. Quat. Sci. 36, 302-311. doi:10.11928/j.issn.1001-7410.2016.02.06[in Chinese, with English summary].

Dai, L., and Zhang, D. (2018). The study of animal bones uncovered from the Houtieying site, Bozhou, Anhui Province. Cultural Relics Southern China 2018 (01), 142-150 [in Chinese, with English summary].

Digard, J.-P. (2006). Essai d'ethno-archeologie du chien. Ethnozootechnie 78, 33-40.

Djamali, M., Biglari, F., Abdi, K., Andrieu-Ponel, V., de Beaulieu, J.-L., Mashkour, M., et al. (2011). Pollen analysis of coprolites from a late Pleistocene-Holocene cave deposit (Wezmeh Cave, west Iran): insights into the late Pleistocene and late Holocene vegetation and flora of the central Zagros Mountains. J. Archaeol. Sci. 38 (12), 3394-3401. doi:10.1016/j.jas.2011.08.001

Dong, Z., Zhang, J., Yang, Y., Yao, L., Li, W., and Jia, Q. (2014). Starch grain analysis reveals the utilization of plant food resources at Shishanzi site, Suixi County, Anhui Province. Quat. Sci. 34, 114-125. doi:10.3969/j.issn.1001-7410. 2014.01.14[in Chinese, with English summary].

Faegri, K., Kaland, P. E., and Krzywinski, K. (1989). Textbook of pollen analysis. 4th Edn. New York, NY: Wiley and Sons. 
Fuller, D. Q., Qin, L., Zheng, Y., Zhao, Z., Chen, X., Hosoya, L. A., et al. (2009). The domestication process and domestication rate in rice: spikelet bases from the lower Yangtze. Science 323 (5921), 1607-1610. doi:10.1126/science.1166605

Fuller, D. Q., and Qin, L. (2009). Water management and labour in the origins and dispersal of Asian rice. World Archaeol. 41 (1), 88-111. doi:10.1080/ 00438240802668321

Germonpré, M., Lázničková-Galetová, M., and Sablin, M. V. (2012). Palaeolithic dog skulls at the Gravettian Předmostí site, the Czech Republic. J. Archaeol. Sci. 39 (1), 184-202. doi:10.1016/j.jas.2011.09.022

Germonpré, M., Sablin, M. V., Stevens, R. E., Hedges, R. E. M., Hofreiter, M., Stiller, M., et al. (2009). Fossil dogs and wolves from palaeolithic sites in Belgium, the Ukraine and Russia: osteometry, ancient DNA and stable isotopes. J. Archaeol. Sci. 36 (2), 473-490. doi:10.1016/j.jas.2008.09.033

Gross, B. L., and Zhao, Z. (2014). Archaeological and genetic insights into the origins of domesticated rice. Proc. Natl. Acad. Sci. U.S.A. 111 (17), 6190-6197. doi:10.1073/pnas.1308942110

Guiry, E. J. (2012). Dogs as analogs in stable isotope-based human paleodietary reconstructions: a review and considerations for future use. J. Archaeol. Method Theor 19 (3), 351-376. doi:10.1007/s10816-011-9118-z

Henan Institute of Cultural Relics and Archaeology (1999). Wuyang Jiahu. Beijing, China: Science Press [in Chinese, with English summary].

Horard-Herbin, M.-P., Tresset, A., and Vigne, J.-D. (2014). Domestication and uses of the dog in western Europe from the paleolithic to the iron Age. Anim. Front. 4 (3), 23-31. doi:10.2527/af.2014-0018

Institute of Archeology of Chinese Academy of Social Sciences, and Museum of Bengbu (2016). "Achievements of excavation of Shuangdun site in Bengbu city, Anhui province during the 2014 and 2015," in Major archaeological discoveries in China. Beijing, China: National Cultural Heritage Administration (Beijing, Heritage Press, , 20-24 [in Chinese, with English summary].

Lai, Y., Zhang, J., and Ying, R. (2009). The prehistoric economy of the site of Jiahu, information from the analysis of the unearthed artifacts. Zhongyuan wenwu 2, 22-28. doi:10.3969/j.issn.1003-1731.2009.02.005[in Chinese, with English summary].

Larson, G., Karlsson, E. K., Perri, A., Webster, M. T., Ho, S. Y., Peters, J., et al. (2012). Rethinking dog domestication by integrating genetics, archeology, and biogeography. Proc. Natl. Acad. Sci. U.S.A. 109 (23), 8878-8883. doi:10.1073/ pnas. 1203005109

Leeming, R., Latham, V., Rayner, M., and Nichols, P. (1997). "Detecting and distinguishing sources of sewage pollution in Australian inland and coastal waters and sediments," in Molecular markers in environmental geochemistry. Editor R. P. Eganhouse (Washington, DC: American Chemical Society), 306-319.

Leeming, R., Ball, A., Ashbolt, N., and Nichols, P. (1996). Using faecal sterols from humans and animals to distinguish faecal pollution in receiving waters. Water Res. 30 (12), 2893-2900. doi:10.1016/s0043-1354(96)00011-5

Li, C., Zheng, Y., Yu, S., Li, Y., and Shen, H. (2012). Understanding the ecological background of rice agriculture on the Ningshao Plain during the Neolithic Age: pollen evidence from a buried paddy field at the Tianluoshan cultural site. Quat. Sci. Rev. 35, 131-138. doi:10.1016/j.quascirev.2012.01.007

Liu, Y., Sun, Q., Fan, D., Lai, X., Xu, L., Finlayson, B., et al. (2016). Pollen evidence to interpret the history of rice farming at the Hemudu site on the Ningshao coast, eastern China. Quat. Int. 426, 195-203. doi:10.1016/j.quaint.2016.05.016

Luan, F. S. (2013). "The Dawenkou culture in the lower Yellow River and Huai River basin areas" in A companion to Chinese Archaeology. Editor A. P. Underhill (Hoboken, NJ: Blackwell Publishing Ltd.), 411-434.

Luo, W., Gu, C., Yang, Y., Zhang, D., Liang, Z., Fang, F., et al. (2018). Phytolith evidence for the development of agriculture between early Dawenkou and Longshan cultures at the Gongzhuang site in Linquan county, Anhui province. Acta Micropalaeontol. Sin. 35 (4), 370-380 [in Chinese, with English summary].

Luo, W., Gu, C., Yang, Y., Zhang, D., Liang, Z., Li, J., et al. (2019). Phytoliths reveal the earliest interplay of rice and broomcorn millet at the site of Shuangdun (ca. 7.3-6.8 ka BP) in the middle Huai River valley, China. J. Archaeol. Sci. 102, 26-34. doi:10.1016/j.jas.2018.12.004

Luo, W., Yang, Y., Zhuang, L., Gan, H., Gu, C., Huang, C., et al. (2020). Phytolith evidence of water management for rice growing and processing between 8500 and $7500 \mathrm{cal}$ years BP in the middle Huai river valley, China. Veg. Hist. Archaeobotany, 1-12. doi:10.1007/s00334-020-00782-2
Lupo, K. D. (2011). "A dog is for hunting” in Ethnozooarchaeology: the present and past of human-animal relationships. Editors U. Albarella and A. Trentacoste (London, United Kingdom: Oxbow Press), 4-12.

Lupo, K. D. (2019). Hounds follow those who feed them: what can the ethnographic record of hunter-gatherers reveal about early human-canid partnerships? J. Anthropol. Archaeol. 55, 101081. doi:10.1016/j.jaa.2019.101081

Lupo, K. D. (2017). When and where do dogs improve hunting productivity? The empirical record and some implications for early Upper Paleolithic prey acquisition. J. Anthropol. Archaeol. 47, 139-151. doi:10.1016/j.jaa.2017.05.003

Méniel, P. (2006). Le chien en Gaule, Animali tra uomini e dei, archeozoologia del mondo preromano. Studi e Scavi 14, 45-52.

Miller, N. F., Spengler, R. N., and Frachetti, M. (2016). Millet cultivation across Eurasia: origins, spread, and the influence of seasonal climate. Holocene 26 (10), 1566-1575. doi:10.1177/0959683616641742

Morey, D. F., and Jeger, R. (2017). From wolf to dog: late Pleistocene ecological dynamics, altered trophic strategies, and shifting human perceptions. Hist. Biol. 29 (7), 895-903. doi:10.1080/08912963.2016.1262854

Nakamura, S.-I. (2010). The origin of rice cultivation in the lower Yangtze region, China. Archaeol. Anthropol. Sci. 2, 107-113. doi:10.1007/s12520-010-0033-0

Ovodov, N. D., Crockford, S. J., Kuzmin, Y. V., Higham, T. F., Hodgins, G. W., van der Plicht, J., et al. (2011). A 33,000-year-old incipient dog from the Altai mountains of Siberia: evidence of the earliest domestication disrupted by the last glacial maximum. PLoS One 6, e22821. doi:10.1371/journal.pone.0022821

Pan, Y. (2011). Resource production of the Yangzi Delta and Qiantang drainage during 10000-6000 BP: paleoethnobotany and human ecology studies. PhD thesis. Fudan (China): Fudan University [in Chinese, with English summary].

Qin, L., Fuller, D., and Zhang, H. (2010). Modelling wild food resource catchments among early farmers: case study from the lower Yangtze and central China. Quat. Sci. 30, 245-261 [in Chinese, with English summary].

Shillito, L. M., Blong, J. C., Green, E. J., and Van Asperen, E. (2020). The what, how and why of archaeological coprolite analysis. Earth Sci. Rev. 207, 103196. doi:10. 1016/j.earscirev.2020.103196

Shoda, S., Lucquin, A., Sou, C. I., Nishida, Y., Sun, G., Kitano, H., et al. (2018). Molecular and isotopic evidence for the processing of starchy plants in Early Neolithic pottery from China. Sci. Rep. 8 (1), 17044-17049. doi:10.1038/s41598018-35227-4

Sistiaga, A., Mallol, C., Galván, B., and Summons, R. E. (2014). The Neanderthal meal: a new perspective using faecal biomarkers. PLoS One 9 (6), e101045. doi:10.1371/journal.pone.0101045

Sistiaga, A., Wrangham, R., Rothman, J. M., and Summons, R. E. (2015). New insights into the evolution of the human diet from faecal biomarker analysis in wild chimpanzee and gorilla faeces. PLoS One 10 (6), e0128931. doi:10.1371/ journal.pone.0128931

Taylor, A., Hutson, J. M., Bryant, V. M., and Jenkins, D. L. (2020). Dietary items in early to late holocene human coprolites from paisley caves, Oregon, USA. Palynology 44 (1), 12-23. doi:10.1080/01916122.2018.1530699

Toker, N. Y., Onar, V., Belli, O., Ak, S., Alpak, H., and Konyar, E. (2005). Preliminary results of the analysis of coprolite material of a dog unearthed from the Van-Yoncatepe necropolis in eastern Anatolia. Turk. J. Vet. Anim. Sci. 29 (3), 759-765.

Tolar, T., and Galik, A. (2019). A study of dog coprolite from late neolithic piledwelling site in Slovenia. Ad 07 (01), 20. doi:10.4236/ad.2019.71002

Vigne, J. D., and Guilaine, J. (2004). Les premiers animaux de compagnie, 8500 ans avant notre ère? ou comment j'ai mangé Mon chat, Mon chien et Mon renard. Anthropozoologica 39 (1), 249-273.

Wang, W., Shu, J., Chen, W., and Ding, J. (2010). Holocene environmental changes and human impact in the Yangtze river delta area, east China. Quat. Sci. 30 (2), 233e244. doi:10.3969/j.issn.1001-7410.2010.02.01 [in Chinese, with English summary].

Wood, J. R., Wilmshurst, J. M., Wagstaff, S. J., Worthy, T. H., Rawlence, N. J., and Cooper, A. (2012). High-resolution coproecology: using coprolites to reconstruct the habits and habitats of New Zealand's extinct upland moa (Megalapteryx didinus). PLoS One 7 (6) e40025. doi:10.1371/journal.pone. 0040025

Yang, Y., Cheng, Z., Li, W., Yao, L., Li, Z., Luo, W., et al. (2016). The emergence, development and regional differences of mixed farming of rice and millet in the upper and middle Huai River Valley, China. Sci. China Earth Sci. 59 (9), 1779-1790. doi:10.1007/s11430-015-5340-3 
Yang, Y., Li, W., Yao, L., Cheng, Z., Luo, W., Zhang, J., et al. 2016). Plant food sources and stone tools' function at the site of Shunshanji based on starch grain analysis. Sci. China Earth Sci. 59 (8), 1574-1582. doi:10.1007/s11430-0165321-9

Yll, R., Carrión, J. S., Marra, A. C., and Bonfiglio, L. (2006). Vegetation reconstruction on the basis of pollen in late pleistocene hyena coprolites from San Teodoro Cave (Sicily, Italy). Palaeogeogr. Palaeoclimatol. Palaeoecol. 237 (1), 32-39. doi:10.1016/j.palaeo.2005.11.027

Yuan, J. (2001). Issues on the origin of livestock in Neolithic China. Wen Wu 5, 51-58 [in Chinese, with English summary].

Yuan, J., and Yang, M. (2004). "Research on animal remains," in Zhejiang provincial institute of relics and archaeology and museum of Xiaoshan. Editor Kuhuqiao (Beijing, China: Cultural Relic Press), 241-270 [in Chinese, with English summary].

Zhang, C., and Hung, H. C. (2013). Jiahu 1: earliest farmers beyond the Yangtze river. Antiquity 87 (335), 46-63. doi:10.1017/S0003598X00048614

Zhang, J., Lu, H., Gu, W., Wu, N., Zhou, K., Hu, Y., et al. (2012). Early mixed farming of millet and rice 7800 years ago in the middle Yellow River region, China. PLoS One 7, e52146-e52148. doi:10.1371/journal.pone.0052146

Zhang, Y. (2015). Animal procurement in the late neolithic of the Yangtze River basin: integrating the fish remains into a case-study from tianluoshan. $\mathrm{PhD}$ thesis. London (United Kingdom): University College London.

Zhang, Y., van Geel, B., Gosling, W. D., McMichael, C. N. H., Jansen, B., Absalah, S., et al. (2019). Local vegetation patterns of a neolithic environment at the site of Tianluoshan, China, based on coprolite analysis. Rev. Palaeobot. Palynol. 271, 104101. doi:10.1016/j.revpalbo.2019.104101

Zhang, Y., Zhang, D., Yang, Y., and Wu, X. (2020). Pollen and lipid analysis of coprolites from Yuhuicun and Houtieying, China: implications for human habitats and diets. J. Archaeol. Sci.: Report 29, 102135. doi:10.1016/j.jasrep.2019.102135
Zhejiang Provincial Institute of Cultural Relics and Archaeology, Yuyao Municipal Council of Cultural Relics Conservation, Hemudu Site Museum (2007). Brief report of the excavation on a neolithic site at Tianluoshan hill in Yuyao city, Zhejiang. Cultural Relics 11, 4-24 [in Chinese, with English summary].

Zheng, Y., Crawford, G. W., Jiang, L., and Chen, X. (2016). Rice domestication revealed by reduced shattering of archaeological rice from the lower Yangtze valley. Sci. Rep. 6, 28136. doi:10.1038/srep28136

Zheng, Y., Sun, G., and Chen, X. (2012). Response of rice cultivation to fluctuating sea level during the Mid-Holocene. Chin. Sci. Bull. 57, 370-378. doi:10.1007/ s11434-011-4786-3

Zong, Y., Chen, Z., Innes, J. B., Chen, C., Wang, Z., and Wang, H. (2007). Fire and flood management of coastal swamp enabled first rice paddy cultivation in east China. Nature 449 (7161), 459-462. doi:10.1038/nature06135

Zuo, X., Lu, H., Jiang, L., Zhang, J., Yang, X., Huan, X., et al. (2017). Dating rice remains through phytolith carbon-14 study reveals domestication at the beginning of the Holocene. Proc. Natl. Acad. Sci. U.S.A. 114 (25), 6486-6491. doi:10.1073/pnas.1704304114

Conflict of Interest: The authors declare that the research was conducted in the absence of any commercial or financial relationships that could be construed as a potential conflict of interest.

Copyright (c) 2021 Zhang, Sun, Zhang, Yang and Wu. This is an open-access article distributed under the terms of the Creative Commons Attribution License (CC BY). The use, distribution or reproduction in other forums is permitted, provided the original author(s) and the copyright owner(s) are credited and that the original publication in this journal is cited, in accordance with accepted academic practice. No use, distribution or reproduction is permitted which does not comply with these terms. 